\title{
Anomalous Findings of Number, Morphology and Size of Permanent Teeth in 7-10 Years Children Living in the Czech Republic
}

\author{
Ginzelová K., Kripnerová T., Dostálová T. \\ Department of Stomatology, Second Faculty of Medicine, Charles University \\ in Prague and University Hospital Motol, Prague, Czech Republic \\ Received December 1, 2012; Accepted April 8, 2013.
}

Key words: Dentistry - Hypodontia - Hyperodontia - Morphological anomalies Size anomalies

\begin{abstract}
Caucasian population, were examined clinically and radiographically. 430 children were aged 7-10 years. Dental anomalies were diagnosed in 14.1\% (61 children) of those observed between 7-10 years. We aimed at numerical anomalies (78.6\% of children with anomalies), morphological anomalies (19.6\% of children with anomalies), size anomalies (3.2\% of children with anomalies) and combinations of diagnoses $(1.4 \%$ reflects the combinations of teeth 2 times calculated in combinations of diagnoses). Congenital numerical variations, i.e. hypodontia and hyperodontia, are among the most common deviations of the permanent dentition. Both conditions can occur as isolated traits or in association with other syndromes. Many studies indicate that hereditary factors are involved in the aetiology of anomalies. Gen MSX1 involves a primary position in mediating interactions between epithelium and mesenchyme in the development of teeth. Occurrence of dental anomalies is not very frequent; problems can arise with diagnosis of those affected teeth. It can be done using Orthopantomogram or Computed Tomography and 3D reconstruction. Some of the children with anomalies may have difficulties in treatment of affected teeth but in most cases the prognosis is good.
\end{abstract}

This study was supported by the project IGA MZCR No. NT: 13351-4.

Mailing Address: Prof. Tat’jana Dostálová, MD., PhD., DSc., MBA, Department of Stomatology, Second Faculty of Medicine, Charles University in Prague and University Hospital Motol, V úvalu 84, 15006 Prague 5, Czech Republic; Phone: +420 224443 100; Fax: +420 224443 102; e-mail: tatjana.dostalova@fnmotol.cz 


\section{Introduction}

Prevalence of dental anomalies and their demonstration was the aim of this study; dental anomalies are not rare and they are interesting. Literature gives different information on the number of dental anomalies (Marková and Teichmanová, 1985; McNamara et al., 1998; Backman and Wahlin, 2001; Merglová and Kilian, 2002). Many studies indicate that hereditary factors are involved in the aetiology (Sottner, 1997; Peck et al., 2002; Kouskoura et al., 2011). Gen MSX1 involves a primary role in mediating interactions between epithelium and mesenchyme in the development of teeth (Sottner, 1997; Kouskoura et al., 2011). Deletion of this gene brings about tooth agenesis (Peck et al., 2002; Kouskoura et al., 2011). About $80 \%$ (excluding the third molars) of hypodontia patients miss one or two teeth (Kouskoura et al. 2011). According to Garib et al. $(2009,2010)$ prevalence rate of agenesis of permanent teeth has significantly increased: maxillary lateral incisors agenesis and lower second premolars agenesis.

We report the year 2011 when we treated 6,043 children. Children were of the Caucasian population, aged from birth to 18 years and represented our regular patients. The 430 children aged $7-10$ years were examined clinically with radiographic imaging (Pasler and Visser, 2003) and Orthopantomogram (OPG) (Figure 1); in those with diagnostic problems the intraoral radiographs (Figure 2) or Computed Tomography (CT) (Figure 3) and 3D (Figure 4) were obtained. We observed all the permanent teeth, third molars excluded. Dental anomalies were diagnosed in 61 children from the total of 430 children.

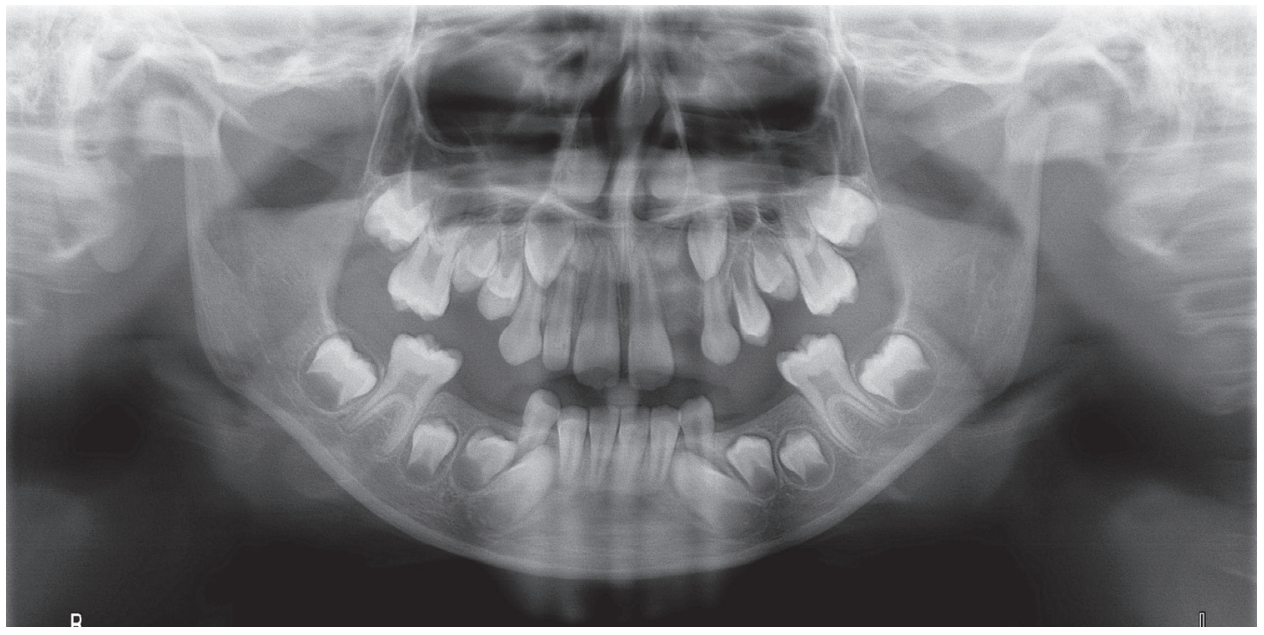

Figure 1 - Orthopantomogram (OPG): dens in dente loco 22. 


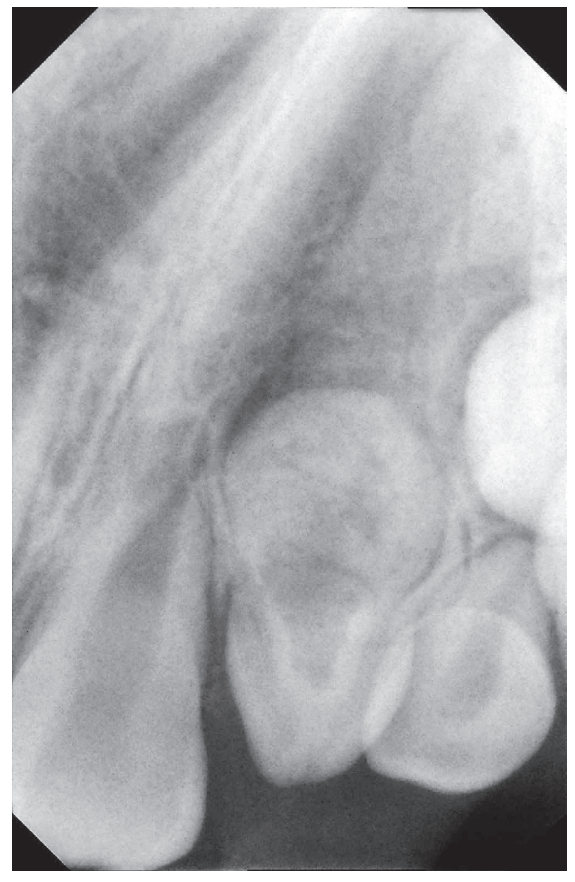

Figure 2 - RTG i.o.: dens in dente loco 22.

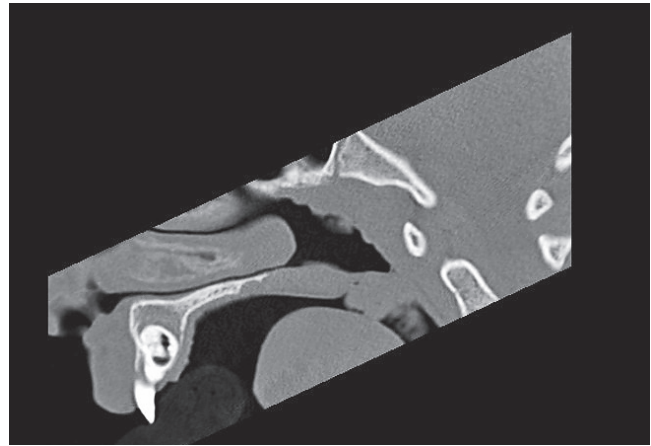

Figure $3-C T$ : dens in dente loco 22.

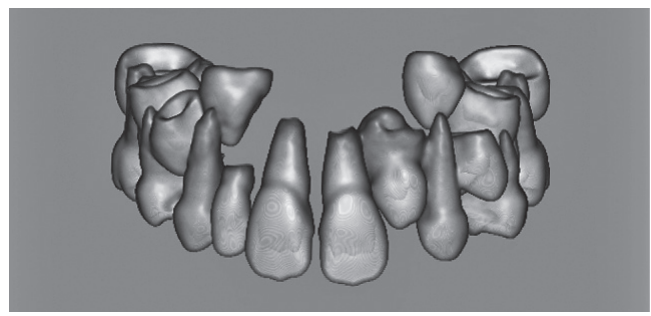

Figure $4-3 D$ : dens in dente loco 22.

\section{Methods}

We observed all permanent teeth, third molars excluded, in 61 children aged 7-10 years. The aim of the study was to evaluate (Winter and Brook, 1989; Regezi and Sciuba, 1993; Šubrtová, 1993; Merglová and Kilian, 2002):

1. Numerical anomalies: they rise due to disorder activity of dentogingival lamina (Pasler and Visser, 2003):

Hypodontia: agenesia, oligodontia: missing more than 6 teeth, anodontia Hyperodontia: supernumerary teeth including mesiodentes, geminations

2. Morphological anomalies: peg-shape, talon cusps and tubercles of Carabelli, dens in dente, taurodontism

3. Size anomalies: microdontia, macrodontia

4. Combinations of diagnoses

\section{Results}

430 children aged 7-10 years were examined; 219 boys (50.9\%) and 211 girls (49.1\%). Only two children had a serious systemic disease (Vicium Cordis Congenita), but it was not evident in any of their dental anomaly. Dental anomalies were diagnosed in 61 children (14.1\% of all examined children) of which 27 were boys (44.2\%) and 34 girls (55.7\%). 4 children had combination of diagnoses, which means two different diagnoses are calculated for only one child. 
1. Numerical anomalies: hypodontia + hyperodontia.

Total number of affected teeth: 106: hypodontia 80 + hyperodontia 26 .

Occurred at number of affected children: 48: hypodontia 33 + hyperodontia 15 .

This is: $78.6 \%$ of affected children, $11.1 \%$ of all examined children.

One boy had also macrodontia loco 21 , he is included to macrodontia group, one girl had also hypodontia loco $15,35,45$, both children are included to hypodontia.

1.1. Hypodontia: agenesia + oligodontia.

Total number of affected teeth (Figure 5): 80: agenesia $72+$ oligodontia 8 .

Occurred at several affected children: 33: agenesia 32 + oligodontia 1 .

This is: $68.7 \%$ of numerical anomalies and $54.1 \%$ of affected children.

1.1.1. Agenesia (Table 1) was diagnosed at 32 children.

This is: $52.4 \%$ of affected children, $7.4 \%$ of all examined children.

1.1.2. Oligodontia was diagnosed at 1 child.

This is: $1.6 \%$ of affected children and $0.2 \%$ of all examined children.

Number of missing teeth: 8.

1.1.3. Anodontia was not diagnosed.
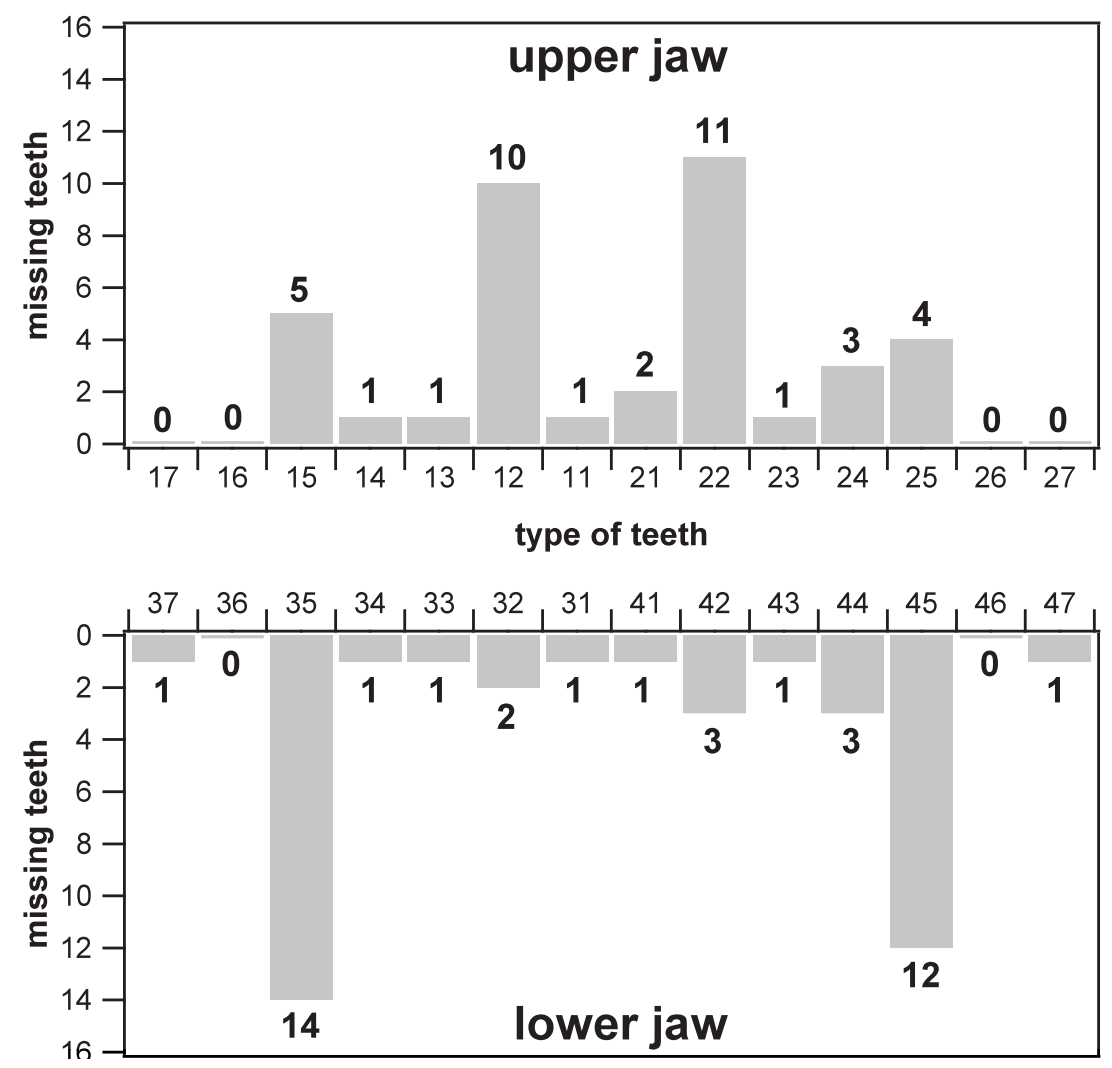

Figure 5 - Place of missing teeth in upper and lower jaws. 


\section{Table 1 - Agenesia}

\begin{tabular}{lcccccc}
\hline \multirow{2}{*}{$\begin{array}{c}\text { Number } \\
\text { of missing teeth }\end{array}$} & \multicolumn{3}{c}{ Number of children } & \multicolumn{3}{c}{ Number of missing teeth } \\
\cline { 2 - 7 } & male & female & total & male & female & total \\
\hline 1 & 7 & 6 & $13(40.6 \%)$ & 7 & 6 & 13 \\
2 & 3 & 6 & $9(28.1 \%)$ & 6 & 12 & 18 \\
3 & 2 & 2 & 4 & 6 & 6 & 12 \\
4 & 1 & 2 & 3 & 4 & 8 & 12 \\
5 & 0 & 1 & 1 & 0 & 5 & 5 \\
6 & 0 & 2 & 2 & 0 & 12 & 12 \\
Total & 13 & 19 & 32 & 23 & 49 & 72 \\
\hline
\end{tabular}

1.2. Hyperodontia: supernumerary teeth + geminations.

Total number of affected teeth: 26: supernumerary $25+$ geminations 1 .

Occurred at several affected children: 15: supernumerary $14+$ geminations 1 .

This is: $24.5 \%$ of affected children, $3.4 \%$ of all examined children, $31.2 \%$ of numerical anomalies.

One boy had also macrodontia loco 21 , he is included to macrodontia group, one girl had also hypodontia loco $15,35,45$, she is included to hypodontia.

1.2.1. Supernumerary teeth including mesiodentes were diagnosed at 16 children (Tables 2 and 3).

This is: $26.2 \%$ of affected children, $3.7 \%$ of all examined children.

1.2.2. Geminations. One girl was diagnosed with gemination loco 31 , it did not change the number of lower incisors, tooth loco 31 is gemination.

Table 2 - Location of supernumerary teeth

\begin{tabular}{lcccccc}
\hline \multirow{2}{*}{$\begin{array}{c}\text { Location of } \\
\text { supernumerary teeth }\end{array}$} & \multicolumn{3}{c}{ Number of children } & \multicolumn{3}{c}{ Number of teeth } \\
\cline { 2 - 7 } & male & female & total & male & female & total \\
\hline mesiodens & 5 & 5 & $10(62.5 \%)$ & 7 & 11 & 18 \\
tooth 12 & 0 & 1 & 1 & 0 & 1 & 1 \\
tooth 21 & 0 & 2 & 2 & 0 & 2 & 2 \\
tooth 22 & 2 & 0 & 2 & 2 & 0 & 2 \\
tooth 32* & $1-1$ & 0 & $1-1$ & 1 & 0 & 1 \\
tooth 41 & 0 & 1 & 1 & 0 & 1 & 1 \\
Total & $8-1$ & 9 & $17-1$ & 10 & 15 & 25 \\
\hline
\end{tabular}

*one boy had 1 mesiodens and 1 supernumerary tooth loco 32 , he is calculated by mesiodens 
Table 3 - Number of supernumerary teeth

\begin{tabular}{|c|c|c|c|c|c|c|}
\hline \multirow{2}{*}{$\begin{array}{c}\text { Number of } \\
\text { supernumerary teeth }\end{array}$} & \multicolumn{3}{|c|}{ Number of children } & \multicolumn{3}{|c|}{ Number of supernumerary teeth } \\
\hline & male & female & total & male & female & total \\
\hline 1 & 4 & 5 & 9 & 4 & 5 & 9 \\
\hline 2 & 3 & 3 & 6 & 6 & 6 & 12 \\
\hline 4 & 0 & 1 & 1 & 0 & 4 & 4 \\
\hline Total & 7 & 9 & 16 & 10 & 15 & 25 \\
\hline
\end{tabular}

2. Morphological anomalies: peg shaped + talon cusps + tubercles of Carabelli + dens in dente.

Total number of affected teeth: 15: peg shaped $8+$ talon cusps $4+$ tubercles of Carabelli $2+$ dens in dente 1.

Occurred in several affected children: 12: peg shaped $7+$ talon cusps $3+$ tubercles of Carabelli $1+$ dens in dente 1.

This is: $19.6 \%$ of affected children and $2.7 \%$ of all examined children.

2.1. Peg-shaped upper lateral incisors were diagnosed at 7 children (Table 4).

This is: $11.3 \%$ of affected children, $1.6 \%$ of all examined children.

2.2. Talon cusps were diagnosed at 3 children (Table 5).

This is: $4.9 \%$ of affected children and $0.6 \%$ of all examined children.

2.3. Tubercles of Carabelli were diagnosed at 1 child on both upper first molars, both teeth each had two tubercles.

This is: $1.6 \%$ of affected children and $0.2 \%$ of all examined children.

2.4. One girl with dens in dente loco 22 was diagnosed, she had loco

12 microdontia too.

The tooth 22 was partly erupted and appeared healthy at the time of the clinical examination. The radiographic examination revealed the dens in dente in the maxillary left lateral incisor. The CT radiographic consultation was completed for the remainder of the tooth.

This is: $1.6 \%$ of affected children and $0.2 \%$ of all examined children.

2.5. Taurodontism was not found.

Table 4 - Peg-shaped upper lateral incisors

\begin{tabular}{|c|c|c|c|c|c|c|}
\hline \multirow{2}{*}{$\begin{array}{l}\text { Number of } \\
\text { peg-shaped }\end{array}$} & \multicolumn{2}{|c|}{ Locate } & \multirow{2}{*}{$\begin{array}{c}\begin{array}{c}\text { Number } \\
\text { of } \mathrm{p}-\mathrm{s} \text { teeth }\end{array} \\
\text { total }\end{array}$} & \multicolumn{3}{|c|}{ Number of children } \\
\hline & 12 & 22 & & male & female & total \\
\hline 1 & 2 & 4 & 6 & 4 & 2 & 6 \\
\hline 2 & $1+$ & & 2 & 1 & 0 & 1 \\
\hline Total & 3 & 5 & 8 & 5 & 2 & 7 \\
\hline
\end{tabular}

$* 1+1$ : it is by one boy 


\section{Table 5 - Talon cusps}

\begin{tabular}{lcccccc}
\hline \multirow{2}{*}{$\begin{array}{c}\text { Number of cusps on } \\
\text { one tooth }\end{array}$} & \multicolumn{2}{c}{ Locate } & $\begin{array}{c}\text { Number of } \\
\text { teeth }\end{array}$ & \multicolumn{3}{c}{ Number of children } \\
\cline { 2 - 7 } & 11 & 21 & total & male & female & total \\
\hline 1 & 1 & 1 & 2 & 0 & 2 & 2 \\
2 & $1+1 *$ & 2 & 1 & 0 & 1 \\
Total & 2 & 2 & 4 & 1 & 2 & 3 \\
\hline
\end{tabular}

$* 1+1$ : it is by one child

3. Size anomalies: microdontia + megadontia.

Total number of affected teeth: 2: microdontia $1+$ macrodontia 1 .

Occurred in two cases: 2: microdontia $1+$ macrodontia 1 .

This is: $3.2 \%$ of affected children and $0.4 \%$ of all examined children.

The girl with dens in dente loco 22 had microdontia diagnosed at loco 12.

Microdontia was classified as dens in dente.

At one boy with megadontia loco 21 hyperodontia loco 22 was also diagnosed, it was classified as hyperodontia.

4. Combinations of diagnoses (Table 6): were diagnosed by 4 children.

This is: $6.5 \%$ of affected children and $0.9 \%$ of all examined children.

\section{Table 6 - Combinations of diagnoses}

\begin{tabular}{llccc}
\hline & \multicolumn{1}{c}{ Leading diagnose } & \multicolumn{3}{c}{ Number of children } \\
\cline { 3 - 5 } Peg-shaped loco 12 & dens in dente 22 & male & female & total \\
\hline Hyperodontia loco & & & 1 & 1 \\
\hline 21 & hypodontia 15, 35, 45 & 0 & 1 & 1 \\
22 & megadontia 21 & 1 & 0 & 1 \\
32 & mesiodens 1 & 1 & 0 & 1 \\
\hline Total hyperodontia & & 2 & 1 & 3 \\
\hline Total number of combinations & 2 & 2 & 4 \\
\hline
\end{tabular}

\section{Discussion}

We examined 430 children 7-10 years old at our study and 61 (14.1\%) of them had some dental anomalies. Uslu et al. (2009) found in orthodontic patients $40.3 \%$ of patients with dental anomaly. The numerical anomalies are the most prevalent according to the literature (Backman and Wahlin, 2001) and we also confirmed it in our study. According to the literature numerical variations are of the multifactorial 
origin, genetic and environmental factors probably participate (Brook, 1984; Sottner, 1997; Backman and Wahlin, 2001; Peck et al., 2002; Kouskoura et al., 2011). The prevalence of hypodontia is $54.1 \%$ of all affected children, which is the highest number of one diagnose in our study. 33 cases with hypodontia represent $7.6 \%$ of all examined and $54.1 \%$ of affected children. Backman and Wahlin (2001) in their study found hypodontia in Swedish population in $7.4 \%$ of visited children. The highest occurrence of hypodontia is in Denmark 8.2\%, and the lowest is in England 4.4\% (Brook, 1984; Aasheim and Ogaard, 1993; Endo et al., 2006); agenesia was the most common with $7.4 \%$ of all examined children by Gupta et al. (2011) $4.19 \%$. The most frequently affected teeth by hypodontia in our children are the permanent lower second premolars; in the literature are the same data (Garib et al., 2010). The most frequently missing teeth in hypodontia group according to our study were incisors 1 and 2, similarly to the study of Endo et al. (2006). The second place belonged to the permanent upper second incisors. By Larmour et al. (2005) patients with Down syndrome have a high prevalence of hypodontia. All our patients with hypodontia had no underlying diseases and they were healthy. The hypodontia is most frequent in girls ( $57.5 \%$ in our study) the same information about higher frequency in girls is also found in the literature (Brook, 1984). The highest number of missing teeth due to hypodontia was 6 teeth: in two girls. One boy with oligodontia did not have 8 teeth. Prevalence of hyperodontia in all examined children is 3.4\%; Backman and Wahlin (2001) found $1.9 \%$, in all affected children is $24.5 \%$. The most frequent supernumerary tooth (Brook et al., 2009) is mesiodens, 62, $5 \%$ of all supernumerary teeth in our study, in the literature (Backman and Wahlin, 2001) it is $78 \%$. In the literature it is possible to find a difference in the number of mesiodentes in relation to sex, Brook (1984) had higher number for boys; Backman and Wahlin (2001) described higher number in girls. In our study the same number of girls and boys with mesiodens was revealed. The highest number of supernumerary teeth is 4 teeth in one patient. Morphological anomalies were diagnosed in 12 children; this is $2.7 \%$ of all examined children and $19.6 \%$ of all affected children. There were diagnosed 8 peg-shaped lateral upper incisors in 7 children, this is $58.3 \%$ of morphological anomalies and it is the most common type in all morphological anomalies. Peg-shaped teeth at both sides occurred in one boy. We observed one girl with the coexistence of a lateral peg-shaped upper right tooth and microdontia in the same location but at the left side. In the literature the coexistence of pegshaped upper lateral incisor and hypodontia is described (Backman and Wahlin, 2001). According to McNamara et al. (1998) talon cusps occur in $90 \%$ in the maxilla and at the maxillary lateral incisor on the palatal surface. It can by an isolated finding or the anomaly could combine with other dental anomalies. Our 3 children had the talon cusps only in maxilla and only by the maxillary central incisors at the palatal surface; one boy had talon cusps at both of them. According to the literature (McNamara et al., 1998) and also in our study tubercles of Carabelli were diagnosed in maxillary first permanent molars. The indicated prevalence of dens in dente 
differs according to various authors. The data are from $0.25 \%$ to $10 \%$ by Chen et al. (1998), by McNamara et al. (1998) to range from $0.25 \%$ to $6.9 \%$, by Backman and Wahlin (2001) the prevalence is about 6-8\%. The prevalence of dens in dente is $0.2 \%$ of all examined children in our study. The permanent maxillary lateral incisors should be the most frequently affected teeth according to Alani and Bishop (2008). Our dens in dente was also found in the permanent maxillary lateral incisor. Megadontia is more common in boys and microdontia in girls (Brook, 1984). The same result revealed also our monitoring. In the literature various combinations of diagnoses by dens in dente are given (Backman and Wahlin, 2001); in our study we found only combination of dens in dente with microdontia. Most of combined diagnoses in our study include hyperodontia.

\section{Conclusion}

Dental anomalies should be solved by dental treatment. Problems can arise in the treatment of these affected teeth. In most cases the treatment prognosis is good. The treatment must be modified in many cases. Emphasis is placed at the appropriate prosthetic treatment of the affected teeth and solution of articulation disorders.

\section{References}

Aasheim, B., Ogaard, B. (1993) Hypodontia in 9-year-old Norwegians related to need of orthodontic treatment. Scand. J. Dent. Res. 101, 257-260.

Alani, A., Bishop, K. (2008) Dens invaginatus. Part 1: Classification, prevalence and aetiology. Int. Endod. J. 41, 1123-1136.

Backman, B., Wahlin, Y. B. (2001) Variations in number and morphology of permanent teeth in 7-year-old Swedish children. Int. J. Paediatr. Dent. 11, 11-17.

Brook, A. H. (1984) A unifying aetiological explanation for anomalies of human tooth number and size. Arch. Oral Biol. 29, 373-378.

Brook, A. H., Griffin, R. C., Smith, R. N., Townsend, G. C., Kaur, G., Davis, G. R., Fearne, J. (2009) Tooth size patterns in patients with hypodontia and supernumerary teeth. Arch. Oral Biol. 54, 63-70.

Chen, Y. H., Tseng, C. C., Harn, W. M. (1998) Dens invaginatus: Review of formation and morphology with 2 case reports. Oral Surg. Oral Med. Oral Pathol. Oral Radiol. Endod. 86, 347-352.

Endo, T., Ozoe, R., Kubota, M., Akiyama, M., Shimooka, S. (2006) A survey of hypodontia in Japanese orthodontic patients. Am. J. Orthod. Dentofacial Orthop. 129, 29-35.

Garib, D. G., Peck, S., Gomes, S. C. (2009) Increased occurrence of dental anomalies associated with secondpremolar agenesis. Angle Orthod. 79, 436-441.

Garib, D. G., Alencar, B. M., Lauris, J. R., Baccetti, T. (2010) Agenesis of maxillary lateral incisors and associated dental anomalies. Am. J. Orthod. Dentofacial Orthop. 17, 732 e1-e6; discussion 732-733.

Gupta, S. K., Saxena, P., Jain, S., Jain, D. (2011) Prevalence and distribution of selected developmental dental anomalies in an Indian population. J. Oral Sci. 53, 231-238.

Kouskoura, T., Fragou, N., Alexiou, M., John, N., Sommer, L., Graf, D., Katsaros, Ch., Mitsiadis, T. A. (2011) The genetic basis of craniofacial and dental abnormalities. Schweiz. Monatsschr. Zahnmed. 121, 636-646.

Larmour, C. J., Mossey, P. A., Thind, B. S., Forgie, A. H., Stirrups, D. R. (2005) Hypodontia - A retrospective review of prevalence and etiology. Part I. Quintessence Int. 36, 263-270. 
Marková, M., Taichmanová, Z. (1985) Incidence of orthodontic anomalies in school children in Prague 10. Acta Univ. Carol. Med. (Praha) 31, 415-433.

McNamara, C. M., Garvey, M. T., Winter, G. B. (1998) Root abnormalities, talon cusps, dentes invaginati with reduced alveolar bone levels: case report. Int. J. Paediatr. Dent. 8, 41-45.

Merglová, V., Kilian, J. (2002) Poruchy vývoje zubů u dětí. Doporučené postupy pro praktické lékaře. Available at: http://www.cls.cz/seznam-doporucenych-postupu

Pasler, F. A., Visser, H. (2003) Taschenatlas der Zahnarztlichen Radiologie. Georg Thieme Verlag, Stuttgart.

Peck, S., Peck, L., Kataja, M. (2002) Concomitant occurrence of canine malposition and tooth agenesis:

Evidence of orofacial genetic fields. Am. J. Orthod. 122, 657-668.

Regezi, J. A., Sciuba, J. (1993) Oral Pathology. W. B. Saunders Company, London.

Sottner, L. (1997) Naše pojetí dědičnosti retence zubů ve světle molekulární biologie a genetiky. Čes. Stomat. 97, 43-51.

Šubrtová, I. (1993) Vybrané Kapitoly z Ortodoncie. Karolinum, Praha.

Uslu, O., Akcam, M. O., Evirgen, S., Cebeci, I. (2009) Prevalence of dental anomalies in various malocclusions. Am. J. Orthod. Dentofacial Orthop. 135, 328-335.

Winter, G. B., Brook, A. H. (1989) A Companion to Dental Studies, Volume 3. Clinical Dentistry. Blackwell Scientific Publications, Oxford. 